\title{
Differences in coping strategies among young adults and the elderly with cancer
}

\author{
Raquel HERNÁNDEZ, ${ }^{1}$ Caterina CALDERON ${ }^{1},{ }^{2}$ Alberto CARMONA-BAYONAS, ${ }^{3}$ \\ Alejandra RODRÍGUEZ CAPOTE ${ }^{1}$ Carlos JARA, ${ }^{4}$ Airam PADILlA ÁlVAREZ, ${ }^{1}$ \\ María de las Nieves GÓMEZ-CAMACHO, ${ }^{1}$ Carmen BEATO,${ }^{5}$ Beatriz CASTELO, ${ }^{6}$ Margarita MAJEM, ${ }^{7}$ \\ María del Mar MUNOZZ, ${ }^{8}$ Alejandra IVARS, ${ }^{3}$ Montserrat MANGAS-IZQUIERDO, ${ }^{9}$ \\ Jacobo ROGADO-REVUELTA ${ }^{10}$ and Paula JIMENEZ-FONSECA ${ }^{11}$
}

\begin{abstract}
${ }^{1}$ Department of Medical Oncology, University Hospital of the Canary Islands, Tenerife, ${ }^{2}$ Department of Clinical Psychology and Psychobiology. Faculty of Psychology, University of Barcelona and ${ }^{7}$ Department of Medical Oncology, University Hospital Santa Creu and Sant Pau, Barcelona, ${ }^{3}$ Department of Medical Oncology, Morales Meseguer University Hospital, Murcia, ${ }^{4}$ Department of Medical Oncology, University Hospital Fundación Alcorcón, Universidad Rey Juan Carlos, ${ }^{6}$ Department of Medical Oncology, University Hospital La Paz and ${ }^{10}$ Department of Medical Oncology, University Hospital La Princesa, Madrid, ${ }^{5}$ Department of Medical Oncology, Hospital Grupo Quirón, Sevilla, ${ }^{8}$ Department of Medical Oncology, Virgen de La Luz Hospital, Cuenca, ${ }^{9}$ Department of Medical Oncology, Galdakao Hospital -Usansolo, Galdakao-Usansolo and ${ }^{11}$ Department of Medical Oncology, University Hospital Central of Asturias, Oviedo, Spain

Correspondence: Caterina Calderon $\mathrm{PhD}$, Department of Clinical Psychology and Psychobiology, Faculty of Psychology, University of Barcelona, Passeig de la Vall d'Hebron, 171, 08035 Barcelona, Spain. Email: ccalderon@ub.edu

Disclosure: The authors have declared no conflict of interest.

Received 12 July 2018; revision received 6 November 2018; accepted 31 December 2018.
\end{abstract}

Key words: cancer, coping, elderly, quality-of-life, shared decision-making, young adult.

\begin{abstract}
Background: Coping with cancer and the oncologist-patient relationship can vary depending on the patient's age. Our aim is to examine and compare young and elderly adults with non-metastatic, resected cancer.

Methods: Two groups of patients were selected, young ( $<40$ years) and elderly $(>70)$ with a diagnosis of non-metastatic, resected cancer requiring adjuvant chemotherapy from a pre-exiting, national database (NEOCOPING Study). Epidemiological variables were collected and subjects' emotional responses, perceptions of the physician-patient relationship, support network, fears, and regret about the decision to receive chemotherapy were assessed with questionnaires validated in previous studies: Mini-Mental Adjustment to Cancer, Brief Summary Inventory (18 items), European Organization for the Research and Treatment of Cancer Quality of Life Questionnaire-C30, Shared Decision-Making Questionnaire-Physician's version, Shared Decision-Making Questionnaire-Patient's version, and Informed Risk (physician and patient versions).

Results: Data from 46 young and 46 elderly participants were collected. The most common neoplasms in both groups were breast $(50 \%)$ and colorectal (22\%). The younger adults had a higher level of education and were actively employed ( $72 \%$ vs. $7 \%$ ). The leading coping strategy in the younger cohort was hope, and resignation among the elderly. Young adults sought more social support and the impact of diagnosis was more negative for them than for older individuals. No significant differences were detected in quality of life; both age groups demanded more time at their first visit with the doctor, while the older group exhibited greater satisfaction with shared decision-making. At the end of adjuvant chemotherapy, neither age group regretted their decision to receive said treatment.

Conclusion: Higher levels of education, greater demands of the labour market, and the advent of the age of information have entailed drastic changes in the physician-patient relationship paradigm. This is especially true in the younger cancer patient population, who require more information and active participation in decision-making, can display more anxiety about their diagnosis, but also greater capacity to fight.
\end{abstract}




\section{INTRODUCTION}

Cancer is a disease that affects all age groups and treatment and information is dispensed in a similar fashion, despite the characteristics of each group that can considerably impact the physician-patient relationship. ${ }^{1}$ The young adults of today have grown up in the age of information, with immediate access to medical terms on the Internet, and ample knowledge of their right to information and autonomy as patients. ${ }^{2}$ Among these individuals, increased knowledge about cancer may lessen their fears and uncertainties regarding their diagnosis. ${ }^{3}$ The elderly, in contrast, grew up at a time when medicine was practised paternalistically, without taking patients' opinions into account when prescribing treatment, expecting them only to comply.

Recent years have seen attempts to delve into coping and the different needs each generational group poses in the light of cancer. Thus, several difficulties have become apparent in each age group, such as the lack of specific, validated questionnaires, the influence of multiple bio-psychosocial variables that modulate coping, and the need to educate and raise awareness among healthcare professionals with a high burden of care about the importance of exploring patients' expectations and adapt our discourse/message to the individual's age. ${ }^{4}$

In the case of young adults, cancer appears at a time in which they are undertaking their life plans, for their professional, social, and family lives. The diagnosis of a neoplasm disrupts these plans and can lead to social isolation, loss of self-esteem, frustration, lack of control, behavioural changes, and resentment. $^{3}$ The literature indicates that the emotional impact of suffering cancer is greater among young adults than the elderly, albeit the latter express their fears less, tend to repress their emotions more, and adjust through passive resignation. ${ }^{5}$

Previous studies reveal younger, previously healthy, independent individuals find it more difficult to assume the role of 'patient, analyzing' which is manifested as a greater tendency toward discontent with the care given, as well as a greater need to be informed and actively participate in decision-making. ${ }^{1}$ These findings indicate that the appropriate information for this age must be provided early in the course of illness, to allay their concerns and fears surrounding how side effects might affect their life and regarding their future prognosis. ${ }^{3}$

Therefore, this study has been designed with the aim of analyzing coping with non-metastatic cancer among younger adults versus elderly patients, the changes that undergoing surgery followed by adjuvant chemotherapy entail, and the needs and perception of shared decision-making between the oncologist and patients in these age groups.

\section{METHODS}

\section{Study design and patients}

A cross-sectional, multi-centre, prospective, noninterventionist study, NEOCOPING, was conducted from July 2015 to March 2017 in 15 medical oncology departments throughout Spain. Eligible patients consisted of younger ( $\leq 40$ years) and elderly ( $>70$ years) cancer patients with complete, curative resection of non-metastatic cancer treated with adjuvant chemotherapy. Individuals with dementia or any other serious mental illness preventing them from understanding the survey were excluded. The study was approved by the Clinical Research Ethics Committee of each centre and all participants provided written, signed, informed consent. Each survey contained written instructions and clearly specified that completing the form was both voluntary and confidential and would not affect their care in any way. Subjects completed the questionnaires individually, with no time limit, without supervision in their oncologist's waiting-room. Selfreport scales were completed by the participants (patients and oncologists) at the beginning of adjuvant treatment.

\section{Measures}

Demographic and clinical characteristics (age; gender, marital status; educational level; occupational sector; tumour site and stage, and time since diagnosis) were collected for statistical purposes.

\section{Mini-Mental Adjustment to Cancer}

The Mini-Mental Adjustment to Cancer (Mini-MAC) ${ }^{1}$ scale is one of the most widely used instruments to measure coping responses in individuals with cancer. The 29-item mini-MAC is a refinement of the original MAC scale, and its brevity allows it to be included within a battery of measures or used in clinical settings. The Spanish version of the Mini-MAC by 
Costa-Requena and Gil was used. $^{6}$ The mini-MAC examines five cognitive coping responses: helplessness-hopelessness (e.g., 'I feel like giving up'), anxious preoccupation (e.g., 'I am apprehensive'), cognitive avoidance (e.g., 'Not thinking about it helps me cope'), fatalism (e.g., 'At the moment I take one day at a time'), and fighting spirit (e.g., 'I see my illness as a challenge'). The numerous studies that have evaluated the mini-MAC's psychometric properties have corroborated the reliability of all five subscales. ${ }^{1,7}$ Nevertheless, studies have also proposed that some of the subscales can be combined to comprise more general coping subscales. Anagnostopoulos et al. $^{3}$ proposed the 'adaptive' (fighting spirit, cognitive avoidance, and fatalism) and 'maladaptive' (helplessness-hopelessness and anxious preoccupation) subscales. Test-retest reliability ranged from 0.62 to 0.99 ; Cronbach's alpha varied between 0.78 to $0.93 .^{4}$

\section{Multidimensional Scale of Perceived Social Support}

The Multidimensional Scale of Perceived Social Support (MSPSS) is a questionnaire that gauges social support ${ }^{8}$ and consists of 12 items related to three sources of social support: family, friends, and significant other. We used the validated Spanish version. ${ }^{9}$ Responses are furnished from 1 (very strongly disagree) to 7 (very strongly agree). The MSPSS is widely used in clinical and non-clinical samples and has proven reliability and validity. ${ }^{10}$

\section{Brief Symptom Inventory}

The Brief Symptom Inventory-18 (BSI-18) ${ }^{11}$ contains 18 items covering three dimensions (somatisation, depression, and anxiety). We used the validated Spanish version. ${ }^{12}$ However, the Global Severity Index (GSI) is the sum of the BSI-18 and summarises the respondent's overall emotional adjustment and psychological distress. Participants answer how they felt over the last 7 days; each item is rated on a fivepoint Likert scale from 0 (not at all) to 4 (extremely). The test-retest reliability ranged from 0.78 to 0.90 . Cronbach's alpha ranged from 0.81 to $0.90 .{ }^{11}$

\section{EORTC QLQ-C30}

The European Organization for the Research and Treatment of Cancer Quality of Life Questionnaire-C30
(EORTC QLQ-C30) is extensively used in Europe and has well-established validity. ${ }^{13}$ It is a modular questionnaire consisting of a core questionnaire (EORTC QLQ-C30) and additional diagnosis-specific modules. ${ }^{14}$ The Spanish version of EORTC QLQ-C30 presented by the EORTC was used for data collection. A sample can be downloaded at the following URL: http://groups.eortc.be/qol/eortc-qlq-c30. Patients must rank each item from 1 (not at all) to 4 (very much). The 30 items of the EORTC QLQ-C30 can be summarised in five functioning scales, 'Physical Functioning', 'Role Functioning', 'Emotional Functioning', 'Social Functioning' and 'Cognitive Functioning' (0, minimum quality of life (QOL); 100 , maximum QOL) and nine symptom scales, for example 'Pain', 'Dyspnoea', 'Insomnia, 'Appetite Loss' and 'Diarrhoea' (0, no symptoms; 100 , severe symptoms).

\section{Shared Decision-Making Questionnaire- Physician's version}

The Shared Decision-Making Questionnaire-Physician's version (SDM-Q-Doc) appraises the physician's opinion as to the degree to which they follow SDM with their patients. ${ }^{15}$ The instrument comprises nine items, each one describing one step of the process; for instance, 'My patient and I thoroughly weighed the different treatment options'. We used the validated Spanish version. ${ }^{16}$ Items are scored 0-5 on a six-point Likert scale as 'completely disagree' (0) to 'completely agree' (5). The total raw score of $0-45$ is the sum of all items. To standardise this raw summary score, the authors recommend using linear transformation to obtain a scale from 0 to 100 (raw score multiplied by 20/9), on which zero indicates the lowest level of perceived SDM. The SDM-Q-Doc exhibits good internal consistency and reliability in German $(\alpha=0.88) .{ }^{17}$

\section{Shared Decision-Making Questionnaire-Patient's version}

The Shared Decision-Making Questionnaire-Patient's version (SDM-Q-9) is a brief, valid, reliable survey that evaluates the SDM process from the patient's perspective. ${ }^{18}$ It was adapted and validated in Spanish by De las Cuevas et al. ${ }^{19}$ and subsequently validated patients with cancer. ${ }^{20}$ It was developed to assess how involved patients feel in the decisionmaking process. Items are scored $0-5$ on a six-point 
Likert scale ranging from 'completely disagree' $(0)$ to 'completely agree' (5). A total raw score of $0-45$ is possible. Multiplication of the raw score by 20 provides a forced score (transformed), ranging from 0 to 100 , where zero indicates the lowest possible level of SDM and 100 indicates the highest. SDM-Q-9 reveals a high Cronbach alpha in Spanish (0.88) patients with cancer. ${ }^{20}$

The Informed Risk (RI) physician and patient ver$\operatorname{sion}^{16}$ is a five-item scale created to ascertain patients' and physicians' degrees of satisfaction with the information provided about the disease, risk of recurrence, treatment side effects, and time dedicated to informing the patient. ${ }^{16}$ The items were scored from zero to 10; the higher the score, the greater the physician's satisfaction with the information provided and time dedicated.

\section{Statistical analyses}

Descriptive statistics were used to summarize demographic data and survey responses. Absolute frequencies were presented for categorical data and means and standard deviations (SD) for quantitative data. Additional descriptive analyses were performed grouping patients by age. We conducted bivariate chi-square and t-tests to assess differences in sociodemographic, clinical, and psychological characteristics between younger vs. older cancer patients. Univariate Analysis of Variance (ANOVA) was used. Statistics were generated with a standard statistical package IBM SPSS Statistics for Windows, version 23.0 (IBM Corp., Armonk, N.Y., USA).

\section{RESULTS}

At the time of data cut-off (June 2017), the study included 92 patients, 46 young adults (14\%) (18 in stage III) and 46 older cancer patients (16 in stage III). Twenty-four medical oncologists from 14 Spanish hospitals participated in this study; $73.1 \%$ were women; mean ages were 36.8 years (SD $=6.9$, range 29-59), and 12.9 years of experience ( $S D=7.5$, range $4-38$ ). No significant differences were found between male and female oncologists with respect to age $(t=1.092$, $P=0.0278)$ or years of experience $(t=1.295$, $P=0.206)$. Most were super-specialists (86.9\%) and worked at a public teaching hospital $(60.2 \%)$.

Baseline characteristics are presented in Table 1. Mean patient age was 36.3 and 72.3 years for younger and older patients, respectively. Both groups contained more women than men (67\% vs. $33 \%)$, with a similar percentage of married individuals $(80 \%$ among younger and $69 \%$ in older participants). However, both groups exhibited different levels of studies; young adults had more academic education, $\chi^{2}=4.073, P=0.044$.

With respect to clinical variables, the most common cancer in both groups was breast $(50 \%)$, followed by colon (22\%). Elderly patients received a single drug treatment regime more than young adults who received two or more drugs, $(72 \%$ vs. $50 \%)$, $\chi^{2}=5.580, P=0.018$. No significant differences between groups were detected in stage of disease at the time of diagnosis, time between onset of symptoms and diagnosis, or risk of relapse.

\section{Psychological adaptation to cancer}

Differences in psychological adaptation by cancer type are reported in Table 2.

\section{Coping with cancer and social support}

The most usual coping strategies were fighting spirit and hopelessness; by and large, members of both groups displayed adaptive coping strategies. Young adults with cancer showed more hope than older patients $\quad\left(F_{1,91}=5.180, \quad P=0.025, \quad\right.$ Cohen's $d=0.4476$ ), whereas the latter revealed more strategies of resignation than the former $\left(F_{1,91}=4.754\right.$, $P=0.032$, Cohen's $d=0.461$ ). As for Support Social, young adults sought more support in their social surroundings than older patients $\left(F_{1,91}=4.295, P=0.041\right.$, Cohen's $d=0.467$ ).

\section{Cancer diagnosis and QOL}

The impact of the diagnosis of cancer was more negative among younger subjects than older ones $\left(F_{1,91}=4.272, P=0.042\right.$, Cohen's $\left.d=0.428\right)$. No significant differences were found in QOL between age groups on any of the subscales.

\section{Shared decision-making and quality of care}

Patients' and oncologists' evaluations of shared decision-making were similar in both age groups; likewise, no significant differences were detected in the assessment of both clinicians and participants of the information provided by the physician or in the time dedicated to the visit. Once adjuvant 
Table 1 Cancer patients' characteristics

\begin{tabular}{|c|c|c|c|c|}
\hline & $\begin{array}{l}\text { Younger } \\
(N=46)\end{array}$ & $\begin{array}{c}\text { Older } \\
(N=46)\end{array}$ & $t / \chi 2$ & $P$ \\
\hline \multicolumn{5}{|l|}{ Gender: $n(\%)$} \\
\hline Women & $15(33)$ & $15(33)$ & 0.000 & 1.000 \\
\hline Men & $31(67)$ & $31(67)$ & & \\
\hline Age, years, mean (SD) & $36.3(4.4)$ & $72.3(7.4)$ & -28.036 & 0.001 \\
\hline \multicolumn{5}{|l|}{ Marital status: $n(\%)$} \\
\hline Married/ partnered & $37(80)$ & $32(69)$ & 1.449 & 0.229 \\
\hline Others & $9(20)$ & $14(31)$ & & \\
\hline \multicolumn{5}{|l|}{ Educational level: $n(\%)^{\dagger}$} \\
\hline Primary & $30(65)$ & $39(91)$ & 4.073 & 0.044 \\
\hline High school or above & $15(35)$ & $7(9)$ & & \\
\hline \multicolumn{5}{|l|}{ Working: $n(\%)$} \\
\hline Active & $33(72)$ & $3(7)$ & 41.071 & 0.001 \\
\hline Retired & $13(28)$ & $43(93)$ & & \\
\hline \multicolumn{5}{|l|}{ Localisation of cancer: $n(\%)$} \\
\hline Colon & $10(22)$ & $10(22)$ & 0.001 & 1.000 \\
\hline Breast & $23(50)$ & $23(50)$ & & \\
\hline Others & $13(28)$ & $13(28)$ & & \\
\hline \multicolumn{5}{|l|}{ Stage: $n(\%)$} \\
\hline I-II & $28(61)$ & $30(65)$ & 0.187 & 0.666 \\
\hline III & $18(39)$ & $16(35)$ & & \\
\hline Time since diagnosis: days (SD) & $124.1(204)$ & $63.1(54.4)$ & 1.688 & 0.099 \\
\hline \multicolumn{5}{|l|}{ Type of treatment: $n(\%)$} \\
\hline $\mathrm{CT}+$ surgery & $24(52)$ & $27(59)$ & 0.396 & 0.529 \\
\hline $\mathrm{CT}+$ surgery + RT & $22(48)$ & $19(41)$ & & \\
\hline Chemotherapy treatment: $n(\%)$ & & & 5.580 & 0.018 \\
\hline Single drug & $23(50)$ & $33(72)$ & & \\
\hline Combination of drugs & $23(50)$ & $13(28)$ & & \\
\hline Risk of relapse & $41.8(18.7)$ & $45.7(25.2)$ & -0.821 & 0.414 \\
\hline
\end{tabular}

Bold values indicate the significant at $5 \%$ level. ${ }^{\dagger}$ Due to a patient not answering this question, the $n$ does not add up to 46 . CT, chemotherapy; RT, radiotherapy,

chemotherapy was completed, neither group regretted their decision to undergo it.

Nevertheless, if we compare doctors' and patients' perceptions of shared decision-making (see Table 3), both were satisfied, albeit physicians $(t=-3.453$, $P<0.001)$ and older patients $(t=-3.191, P<0.001)$ scored it better. Physicians were more satisfied than their patients with the information they had given regarding informed risk in both young adults $(t=-14.071, \quad P<0.001) \quad$ and $\quad$ older individuals $(t=-10.525, P<0.001)$.

Even though $80 \%$ of the doctors indicated that they had dedicated an average of $45 \mathrm{~min}$ to the visit, both younger and older participants felt they had needed more time $(t=-3.511, \quad P<0.001$, $t=-3.186, P=0.003$, respectively).

\section{DISCUSSION}

Young adult and elderly cancer sufferers are two, traditionally underrepresented age groups in clinical trials and epidemiological studies. This void in the literature is the main motivation in conducting this analysis which compares coping in these two groups of subjects with surgically treated, non-metastatic cancer and examines the need for an approach suited to their specific circumstances and to the physical, emotional, and social consequences of overcoming cancer in each age group.

Insofar as sociocultural surroundings are concerned, as expected, the young adult patients have more academic education and tend to be employed, whereas the elderly are retired or unemployed. Among the former, the stress that follows diagnosis is compounded by the economic challenges posed by the costs associated with integral care for their disease, as well as the possible loss of their ability to work while receiving adjuvant chemotherapy. This is why it is important, particularly in young adults, to assess professional aspirations and the need to remain active to conserve their lifestyle and employment once they have finished treatment, and to 
Table 2 Differences in impact of cancer, coping strategies, social support, quality of life, shared decision-making, and well-being by groups

\begin{tabular}{|c|c|c|c|c|c|}
\hline & $\begin{array}{c}\text { Younger } \\
(N=46) \\
\mathrm{M}(\mathrm{SD})\end{array}$ & $\begin{array}{c}\text { Older } \\
(N=46) \\
M(S D)\end{array}$ & $F$ & $P$ & Effect size \\
\hline \multicolumn{6}{|l|}{ Coping with cancer (Mini-MAC) } \\
\hline Fight & $77.5(20.7)$ & $73.1(18.8)$ & 1.106 & 0.296 & --- \\
\hline Hopelessness & $83.7(16.8)$ & $75.1(19.3)$ & 5.180 & 0.025 & 0.476 \\
\hline Anxiety & $47.1(22.9)$ & $45.2(25.9)$ & 0.126 & 0.724 & --- \\
\hline Resignation & $60.2(22.0)$ & $69.7(19.2)$ & 4.754 & 0.032 & 0.461 \\
\hline Avoidance & $55.1(29.8)$ & $54.7(23.1)$ & 0.004 & 0.948 & --- \\
\hline \multicolumn{6}{|l|}{ Social support (MSPSS) } \\
\hline Family & $25.3(3.2)$ & $25.0(3.7)$ & 0.597 & 0.223 & --- \\
\hline Friends & $24.1(4.5)$ & $22.5(4.7)$ & 2.751 & 0.101 & --- \\
\hline Social & $26.1(3.3)$ & $24.3(4.4)$ & 4.295 & 0.041 & 0.467 \\
\hline Psychological distress $(\mathrm{BSI})^{\dagger}$ & $67.2(6.9)$ & $64.2(7.1)$ & 4.272 & 0.042 & 0.428 \\
\hline \multicolumn{6}{|l|}{ Quality of life } \\
\hline Functional scale & $41.4(11.2)$ & $39.6(11.7)$ & 0.617 & 0.434 & --- \\
\hline Symptom scale & $38.8(10.9)$ & $35.8(12.5)$ & 0.257 & 0.613 & --- \\
\hline Health status & $73.3(17.2)$ & $74.3(16.1)$ & 0.097 & 0.757 & --- \\
\hline Quality of life & $58.6(5.7)$ & $58.4(5.8)$ & 0.567 & 0.453 & --- \\
\hline \multicolumn{6}{|l|}{ Shared decision-making } \\
\hline Physician’s version & $92.5(8.3)$ & $89.1(10.0)$ & 2.882 & 0.093 & --- \\
\hline Patient's version & $80.3(19.3)$ & $75.2(20.7)$ & 1.436 & 0.234 & --- \\
\hline \multicolumn{6}{|l|}{ Informed risk (physician) } \\
\hline Satisfaction with information & $98.2(6.4)$ & $97.4(29.3)$ & 0.036 & 0.850 & --- \\
\hline Time & $90.6(29.3)$ & $89.7(30.7)$ & 0.910 & 0.343 & --- \\
\hline \multicolumn{6}{|l|}{ Informed risk (patient) } \\
\hline Satisfaction with information & $67.5(12.1)$ & $67.0(14.1)$ & 0.170 & 0.682 & --- \\
\hline Time & $72.2(20.3)$ & $67.3(23.2)$ & 0.021 & 0.405 & --- \\
\hline Regret & $12.2(13.1)$ & $19.7(23.3)$ & 1.450 & 0.236 & --- \\
\hline
\end{tabular}

Bold values indicate the significant at $5 \%$ level. ${ }^{\dagger}$ T-score. M, mean; Mini-MAC, Mini-Mental Adjustment to Cancer; MSPSS, Multidimensional Scale of Perceived Social Support; BSI, Brief Symptom Inventory

Table 3 Differences in quality of care by physician and patient groups

\begin{tabular}{|c|c|c|c|c|}
\hline & $\begin{array}{c}\text { Physicians } \\
\text { M (SD) }\end{array}$ & $\begin{array}{c}\text { Patients } \\
\text { M (SD) }\end{array}$ & $t$ & $P$ \\
\hline \multicolumn{5}{|l|}{ Young patients } \\
\hline Shared decision-making & $92.5(8.3)$ & $81.4(18.6)$ & -3.453 & 0.001 \\
\hline \multicolumn{5}{|l|}{ Informed risk } \\
\hline Satisfaction with information & $98.2(12.4)$ & $67.6(12.4)$ & -14.071 & 0.001 \\
\hline Time & $90.6(29.3)$ & $71.8(20.9)$ & -3.511 & 0.001 \\
\hline \multicolumn{5}{|l|}{ Older patients } \\
\hline Shared decision-making & $89.1(10.0)$ & $76.5(21.1)$ & -3.191 & 0.003 \\
\hline \multicolumn{5}{|l|}{ Informed risk } \\
\hline Satisfaction with Information & $97.2(11.4)$ & $66.8(14.2)$ & -10.525 & 0.001 \\
\hline Time & $89.7(30.7)$ & $67.3(25.1)$ & -3.186 & 0.003 \\
\hline
\end{tabular}

Bold values indicate the significant at $5 \%$ level. $M$, Mean

provide social support to adapt their job to their abilities and limitations while they undergo treatment and gradually readjust once therapy has concluded. Moreover, treatment for cancer tends to be more aggressive in younger patients; therefore, sequelae are potentially greater, longer lasting and more likely to interfere with their job and social interactions. ${ }^{21}$

As for tumour characteristics, no significant differences were encountered regarding the stage of disease, time between onset of symptoms and diagnosis, type of treatment, or risk of relapse. Therefore, the differences between age groups in coping with their cancer and perception of their relationship with the oncologist may be due more to sociodemographic factors than specific factors stemming from the disease itself.

Our study has evinced that young adults are harder hit by the impact of cancer, exhibiting more 
psychological stress than the elderly. Cancer forces younger patients especially to reconsider many aspects of their lives, changing plans and projects for an indefinite period of time, causing a loss of independence, as well as other, secondary issues, such as economic difficulties, changes in their appearance, and work restrictions. This generates strong feelings of frustration, isolation, sadness, anger, fury, and hopelessness. ${ }^{5,10,17}$ In contrast, they also have more psychological resources than the elderly to fight and cope with this period, turning resentment into a feeling of confrontation and fight, accepting their reality, and conveying optimism. ${ }^{17}$

In our study, the most widely used coping strategy among young adults was hope, whereas seniors used more resignation. This ties in with the fact that young adults typically demand more information about treatment strategies and prognosis, which would engender a fighting spirit. Our results are backed by those of a study carried out in 380 oncological patients at hospitals in northwest England where the younger population expressed a greater need for information about their illness, as well as more emotional, identity, and spiritual concerns than the older ones. ${ }^{15}$ Conversely, other studies have revealed that the elderly experience less psychological distress after being diagnosed with cancer, enabling them to adapt better to it. $^{22,23}$ One study performed in Newcastle among adults who had survived childhood cancer showed that their experience with the disease had affected their overall perspectives, giving them a greater appreciation for life and other people, since they had realised that life can be both short and uncertain. ${ }^{24}$ Rosenberg et al. concluded that the resilience of young people recently diagnosed with cancer is directly associated with their personal resources and learned abilities: stress management, goal-setting, positive reframing, searching for benefits, social support, and maintaining relationships with relatives and peers. ${ }^{25}$ One recent study on depression in cancer survivors found no difference in the rates of clinically relevant depression between the younger and older adult cohorts, although there was a trend toward more depression among the younger patients. Women and Hispanic/Latin patients, regardless of age, revealed a higher prevalence of depression. ${ }^{26}$

In our series, young adults sought more support from their peers. Some works have reported that young adults need continuous and greater support than older ones, not only from healthcare professionals, but also from family and from their social group and friends. ${ }^{27,28}$ It will only be possible to maintain this support network when the patient is able to have an active, positive attitude in this new situation in their life with the maximum support of professionals, relatives, friends, and society who must understand the greater necessity for care and support because of their diagnosis of cancer. ${ }^{3,29,30}$

In recent years, we have witnessed a paradigm shift in the physician-patient relationship, from a 'paternalistic' attitude, in which the clinician determined complementary testing and the treatment plan, toward an approach in which the specialist must provide all the information available so that the patient can decide what the best choice is based on their right to autonomy. ${ }^{1,7}$ Although differences across countries do exist, a poll conducted in eight European countries revealed that most patients wanted to receive more information and participate more actively in the decision-making process. Nevertheless, their expectations surrounding said participation differed significantly from one country to the next; for instance, in Spain and Poland, the participants preferred a more paternalistic model than in Switzerland or Germany. ${ }^{31}$ Numerous studies have demonstrated that shared decision-making enhances physician-patient rapport, response to treatment, as well as the patient's QOL, especially within a context like cancer. ${ }^{4}$ Nevertheless, comparing the opinions of doctors and patients in our study, physicians are satisfied with shared decisionmaking, with the information they provide, and the time they dedicate to the subject. Patients do not agree, as both younger and older adults would like to participate more in making decisions and have more information and time, even when in most cases (80\%), the visit lasted more than $45 \mathrm{~min}$. A more qualitative type of study would be needed to analyze these differences, as well as whether the dissatisfaction was due to the lack of information received or to the way in which it was provided.

Studies performed in primary care have revealed the fact that many patients do not ask all the questions they would have wanted to, expressing the need for a longer appointment. ${ }^{32,33}$ This can be due to the idea from the studies by Ley et al. ${ }^{32}$ according to which the patient would forget $30-50 \%$ of the information given because of the tremendous impact of the diagnosis of cancer, treatment complexity, and 
uncertainty around being cured. On the other hand, understanding how much the patient wants to know and how to communicate best with each one based on age and other biopsychosocial variables are other aspects to be taken into account.

This study has several limitations. The first is that, although higher than in other studies published and with a large total sample size, the number of young adult patients is limited. The second is that these are results from subjects in a single country. The third is that the information was obtained at a given time, during the visit to medical oncology to initiate adjuvant chemotherapy, without being able to ascertain timedependent, intra-individual variability. An additional limitation has to do with the administration of a long protocol, completed in the physician's waiting room, and that may have contributed to respondent's fatigue and abandonment of the questionnaire, ${ }^{31}$ particularly in older patients who need more time to answer the questions. In order to decrease this bias in future studies, the questions could be read to those patients who need it or the protocol could be administered in two stages; alternatively, they could be allowed to fill it in at home.

In short, young adults with non-advanced, resected cancer beginning adjuvant chemotherapy exhibit greater psychological distress than the elderly, as well as hope-based coping, whereas older patients display an attitude of resignation. Both groups would like to participate more in shared decision-making regarding the advisability of adjuvant chemotherapy, receive more information, and have more time for it.

\section{ACKNOWLEDGMENTS}

The authors would like to thank the investigators of the NEOCOPING study (coping, shared decisionmaking and quality of life in patients with early stage cancer treated with adjuvant chemotherapy) and the Supportive Care Working Group of the Spanish Society of Medical Oncology (SEOM).

This work was funded by the SEOM in 2015. The sponsor of this research has not participated in data collection, analysis, or interpretation, in writing the report, or in the decision to submit the article for publication.

\section{REFERENCES}

1 Watson M, Law MG, Santos MD, Greer S, Baruch J, Bliss J. The Mini-MAC: further development of the mental adjustment to cancer scale. J Psychosoc Oncol 1994; 12: 33-46.
2 Lee C, Gray SW, Lewis N. Internet use leads cancer patients to be active health care consumers. Patient Educ Couns 2010; 81: S63-S69. https://doi.org/10.1016/j.pec.2010.09.004.

3 Anagnostopoulos F, Kolokotroni P, Spanea E, Chryssochoou M. The Mini-Mental Adjustment to Cancer (Mini-MAC) scale: construct validation with a Greek sample of breast cancer patients. Psychooncology 2006; 15: 79-89. https://doi.org/10. 1002/pon.924.

4 Pereira FMP, Santos CSV de B. Initial validation of the MiniMental Adjustment to Cancer (Mini-MAC) scale: study of Portuguese end-of-life cancer patients. Eur J Oncol Nurs 2014; 18: 534-539. https://doi.org/10.1016/j.ejon.2014.04.004.

5 Hughes N, Closs SJ, Clark D. Experiencing cancer in old age: a qualitative systematic review. Qual Health Res 2009; 19: 11391153. https://doi.org/10.1177/1049732309341715.

6 Costa-Requena G, Gil F. The Mental Adjustment to Cancer scale: a psychometric analysis in Spanish cancer patients. Psychooncology 2009; 18: 984-991. https://doi.org/10.1002/pon. 1466.

7 Grassi L, Travado L, Moncayo FLG, Sabato S, Rossi E. Psychosocial morbidity and its correlates in cancer patients of the Mediterranean area: findings from the Southern European Psycho-Oncology Study. J Affect Disord 2004; 83: 243-248. https://doi.org/10.1016/j.jad.2004.07.004.

8 Zimet GD, Powell SS, Farley GK, Werkman S, Berkoff KA. Psychometric characteristics of the Multidimensional Scale of Perceived Social Support. J Pers Assess 1990; 55: 610-617. https://doi.org/10.1080/00223891.1990.9674095.

9 Landeta O, Calvete E. Adaptación y validación de la escala Multidimensional de Apoyo Social Percibido. Ansiedad y Estrés 2002; 8: 173-182.

10 Matzka M, Mayer H, Köck-Hódi S et al. Relationship between resilience, psychological distress and physical activity in cancer patients: a cross-sectional observation study. PLoS One 2016; 11: e0154496. https://doi.org/10.1371/journal.pone.0154496.

11 Derogatis LR. BSI 18, Brief Symptom Inventory 18: Administration, Scoring and Procedures Manual. Minneapolis: NCS Pearson, Inc, 2001.

12 Andreu Y, Galdón MJ, Dura E et al. Psychometric properties of the Brief Symptoms Inventory-18 (Bsi-18) in a Spanish sample of outpatients with psychiatric disorders. Psicothema 2008; 20: 844-850.

13 Aaronson NK, Ahmedzai S, Bergman B et al. The European Organization for Research and Treatment of Cancer QLQ-C30: a quality-of-life instrument for use in international clinical trials in oncology. J Natl Cancer Inst 1993; 85: 365-376.

14 Shih C-L, Chen C-H, Sheu C-F, Lang H-C, Hsieh C-L. Validating and improving the reliability of the EORTC QLQ-C30 using a multidimensional Rasch model. Value Heal 2013; 16: 848854. https://doi.org/10.1016/j.jval.2013.05.004.

15 Scholl I, Kriston L, Dirmaier J, Buchholz A, Härter M. Development and psychometric properties of the Shared Decision Making Questionnaire - physician version (SDM-Q-Doc). Patient Educ Couns 2012; 88: 284-290. https://doi.org/10.1016/j.pec. 2012.03.005.

16 Calderon C, Ferrando PJ, Carmona-Bayonas A et al. Validation of SDM-Q-Doc Questionnaire to measure shared decision-making physician's perspective in oncology practice. Clin Trans/ Oncol 2017. https://doi.org/10.1007/s12094-017-1671-9.

17 Scholl I, Kriston L, Dirmaier J, Härter M. Comparing the nineitem Shared Decision-Making Questionnaire to the OPTION Scale - an attempt to establish convergent validity. Heal Expect 2015; 18: 137-150. https://doi.org/10.1111/hex.12022. 
18 Kriston L, Scholl I, Hölzel L, Simon D, Loh A, Härter M. The 9item Shared Decision Making Questionnaire (SDM-Q-9). Development and psychometric properties in a primary care sample. Patient Educ Couns 2010; 80: 94-99. https://doi.org/10.1016/j. pec.2009.09.034.

19 De las Cuevas C, Perestelo-Perez L, Rivero-Santana A, CebollaMartí A, Scholl I, Härter M. Validation of the Spanish version of the 9-item Shared Decision-Making Questionnaire. Heal Expect 2015; 18: 2143-2153. https://doi.org/10.1111/hex.12183.

20 Calderon C, Jiménez-Fonseca P, Ferrando PJ et al. Psychometric properties of the Shared Decision-Making Questionnaire (SDM-Q-9) in oncology practice. Int J Clin Heal Psychol 2018; 18: 91-188. https://doi.org/10.1016/j.ijchp.2017.12.001.

21 Zebrack BJ. Psychological, social, and behavioral issues for young adults with cancer. Cancer 2011; 117: 2289-2294. https://doi.org/10.1002/cncr.26056.

22 Mah K, Tran KT, Gauthier LR et al. Do correlates of pain-related stoicism and cautiousness differ in younger and older people with advanced cancer? J Pain 2018; 19: 301-316. https://doi. org/10.1016/j.jpain.2017.11.002.

23 Muñoz-Sánchez MM, Calderon C, Jimenez-Fonseca $P$ et al. Prospective analysis of psychological differences between adult and elderly cancer patients during postoperative adjuvant chemotherapy. Clin Trans/ Oncol 2018; 20: 1604-1611. https:// doi.org/10.1007/s12094-018-1901-9.

24 Brown MC, Pearce MS, Bailey S, Skinner R. The long-term psychosocial impact of cancer: the views of young adult survivors of childhood cancer. Eur J Cancer Care (Engl) 2016; 25: 428439. https://doi.org/10.1111/ecc.12380.

25 Rosenberg AR, Wolfe J. Approaching the third decade of paediatric palliative oncology investigation: historical progress and future directions. Lancet Child Adolesc Heal 2017; 1: 56-67. https://doi.org/10.1016/S2352-4642(17)30014-7.

26 Bevilacqua LA, Dulak D, Schofield E et al. Prevalence and predictors of depression, pain, and fatigue in older- versus younger-adult cancer survivors. Psychooncology 2018; 27: 900-907. https://doi.org/10.1002/pon.4605.

27 Carstensen LL, Turan B, Scheibe S et al. Emotional experience improves with age: evidence based on over 10 years of experience sampling. Psychol Aging 2011; 26: 21-33. https://doi.org/ $10.1037 / a 0021285$.

28 Keegan THM, Lichtensztajn DY, Kato I et al. Unmet adolescent and young adult cancer survivors information and service needs: a population-based cancer registry study. J Cancer Surviv 2012; 6: 239-250. https://doi.org/10.1007/s11764-0120219-9.

29 Snyder CF, Wu AW, Miller RS, Jensen RE, Bantug ET, Wolff AC. The role of informatics in promoting patient-centered care. Cancer J 2011; 17: 211-218. https://doi.org/10.1097/PPO. Ob013e318225ff89.

30 McCorkle R, Ercolano E, Lazenby $\mathrm{M}$ et al. Self-management: enabling and empowering patients living with cancer as a chronic illness. CA Cancer J Clin 2011; 61: 50-62. https://doi. org/10.3322/caac.20093.

31 Coulter A, Parsons S, Askham J. Where are the patients in decision-making about their own care? Copenhagen: World Health Organization, 2008.

32 Ley P. Memory for medical information. Br J Soc Clin Psychol 1979; 18: 245-255. https://doi.org/10.1111/j.2044-8260.1979. tb00333.x.

33 Peytchev A. Survey breakoff. Public Opin Q 2009; 73: 74-97. 